\title{
DRUG PROVOCATION TEST AS A DIAGNOSTIC APPROACH FOR HYPERSENSITIVITY REACTION TO ANTITUBERCULOSIS DRUGS: A REPORT OF TWO CASES
}

\author{
KETUT SURYANA* \\ Department of Internal Medicine, Merpati Clinic HIV, Allergy-Clinical Immunology Services Unit, Wangaya Hospital, Denpasar, Bali, \\ Indonesia. Email: ketutsuryana@gmail.com
}

Received: 23 February 2020, Revised and Accepted: 24 March 2020

\begin{abstract}
Pulmonary tuberculosis (PTB) continues to be a public health problem, especially in developing countries. The necessity use of multidrug regimens of antituberculosis drug (ATD) in PTB treatment has been associated with increased risk of drug hypersensitivity reactions (DHRs). DHR is a type of unpredictable reaction, refers to immunologically mediated hypersensitivity reactions. It is observed more frequently in the intensive phase of the PTB treatment with varying degrees of severity. DHR can lead to reduce the patient adherence, thereby leading to stoppage of the drugs by the patient. The definite diagnosis based on drug provocation test (DPT) that should be performed at a hospital. The recommended therapeutic approach is rapid desensitization by reintroducing drugs in safety and optimal under threshold dose until usual daily dose is reached. We present two cases of DHR to ATD, DPT as the diagnosis and rapid desensitization as the therapeutic approach.
\end{abstract}

Keywords: Antituberculosis drug, Drug hypersensitivity reaction, Drug provocation test, Rapid desensitization.

(C) 2020 The Authors. Published by Innovare Academic Sciences Pvt Ltd. This is an open access article under the CC BY license (http://creativecommons. org/licenses/by/4. 0/) DOI: http://dx.doi.org/10.22159/ajpcr.2020.v13i5.37248

\section{INTRODUCTION}

Pulmonary tuberculosis (PTB) is a chronic granulomatous infectious disease caused by Mycobacterium tuberculosis [1-3]. PTB is a common health problem and is a leading cause of mortality worldwide. There were estimated 10.4 million of incident cases in 2015 and in Indonesia were estimated 1.02 million of incident cases in 2016 [4-6]. PTB also is a challenge for health-care providers worldwide, especially in developing countries. There are some kind regimens antituberculosis drug (ATD) to treat mycobacterial infections. The necessity consuming multidrug regimens has been related with increased risk of drug hypersensitivity reactions (DHRs). DHR is an unpredictable reaction and it refers to an immunologically mediated hypersensitivity reaction. It may be either immunoglobulin E (IgE) mediated or non-IgE mediated, immediate or delayed hypersensitivity reaction [7-9]. DHR may be mild, life threatening, it is a challenge for the physicians. Awareness of the risk groups may reduce the incidence of serious drug-related hypersensitivity reactions [10-12]. We confirmed the component of ATD that induced DHR by performing drug provocation test (DPT). Rapid desensitization is a therapeutic approach, by reintroducing drug in safety and optimal under-threshold dose until the usual daily dose is reached [13-15].

We present two cases of DHR related to ATD, the challenges of diagnostic and treatment.

\section{CASE REPORT}

We present two cases of DHR to ATD collected in the outpatient Department of Internal Medicine, Merpati Clinic, HIV, Allergy and Clinical Immunology Services Unit at Wangaya Hospital in Denpasar, Bali, Indonesia. We collect the data from two patients who visited Wangaya Hospital, in Denpasar, Bali, Indonesia. Written informed consent was obtained from the patients.

\section{Case-1}

A 27-year-old male patient attended to Wangaya Hospital because he had experienced a generalized urticaria and pruritus, 60 min after taking ATD orally (450 mg rifampicin, $1000 \mathrm{mg}$ pyrazinamide, $750 \mathrm{mg}$ ethambutol, $400 \mathrm{mg}$ isoniazid, and $10 \mathrm{mg}$ pyridoxine) as a single dose for PTB treatment. The patient presented overall an optimal condition with stable hemodynamic. During the anamnesis, he had a history of drug allergy, but the offending drug was unclear. Based on history taking and clinical manifestation, the diagnosis was a mild DHR related to ATD (Table 1).

The treatment for the patient (Case-1) was by discontinuing the ATD immediately and giving orally $4 \mathrm{mg}$ methylprednisolone twice daily and $10 \mathrm{mg}$ loratadine once daily for 3 days treatment.

The diagnosis of offending drugs based on a clinical history and DPT at hospital. DPT consisted of ingesting or injecting in increasing doses of the offending drug once every 30 min until the usual daily dose was administered or symptoms of DHR occurred. The controlled administration of the drug (each component of ATD, such as isoniazid, ethambutol, pyrazinamide, and rifampicin) to patient with a history suggesting a DHR. This drug was either an alternative, structurally, or pharmacologically related drug or the suspected drug itself [16-18].

Ideally, before DPT, the patient should be clinically stable (no signs and symptoms of DHR). After 5 days clinically stable (wash period), the patient returned to hospital for DPT of ATD. The patient signed an informed consent form and admitted for 1 day care for DPT. There was no DHR related to ethambutol, pyrazinamide, and rifampicin during performed the DPT. There was DHR related to isoniazid (Case 1). DHR occurred at the step 3 of DPT, cumulative time $60 \mathrm{~min}$, drug concentration 3/10, with the dose was $120 \mathrm{mg}$ (threshold dose). DPT result was considered positive because there were some symptoms or signs of an immediate DHR as described previously documented (generalized urticaria and pruritus) at about $60 \mathrm{~min}$ after the first dose was administered. DPT determined the offending drug and the safety and optimal under-threshold dose. The safe and optimal underthreshold dose of isoniazid on DPT was one step below the dose on step 3 when DHR occurred. The dose was $80 \mathrm{mg}$ isoniazid (Table 2).

Therefore, rapid desensitization with modified dose or the estimation of safe and optimal under-threshold dose performed by giving $80 \mathrm{mg}$ isoniazid every $30 \mathrm{~min}$ until the usual daily dose was reached $(400 \mathrm{mg}$ isoniazid) (Table 3). 
Table 1: Data of the patient (Case 1)

\begin{tabular}{|c|c|c|c|c|c|c|c|}
\hline Case & Sex & Age (years) & ATD regimen & IgE total $(\mu \mathrm{g} / \mathrm{L})$ & Onset of reaction & Clinical manifestation & Diagnosis \\
\hline 1 & Male & 27 & $\begin{array}{l}\text { ATD: } \\
450 \mathrm{mg} \text { rifampicin, } \\
1000 \mathrm{mg} \text { pyrazinamide, } \\
750 \mathrm{mg} \text { ethambutol, } \\
400 \mathrm{mg} \text { isoniazid, } \\
10 \mathrm{mg} \text { pyridoxine } \\
\text { As a single dose }\end{array}$ & 287 & $60 \mathrm{~min}$ & $\begin{array}{l}\text { Generalized } \\
\text { Urticaria, pruritus } \\
\text { History; } \\
\text { Drug allergy (+) } \\
\text { The offending drug was unclear }\end{array}$ & Mild DHR \\
\hline
\end{tabular}

ATD: Antituberculosis drug, DPT: Drug provocation test, DHR: Drug hypersensitivity reaction

Table 2: Drug provocation test of $400 \mathrm{mg}$ isoniazid

\begin{tabular}{lllllll}
\hline Step & Time (min) & Cumulative time (min) & Drug concentration & Dose (mg) & Cumulative dose (mg) & DHR \\
\hline 1 & 0 & 0 & $1 / 10$ & 40 & 40 & Mild DHR (+) \\
2 & 30 & 30 & $2 / 10$ & 80 & 120 \\
$3^{*}$ & 30 & 60 & $3 / 10$ & 120 & 240 & 320 \\
4 & 30 & 90 & $2 / 10$ & 80 & 400 \\
5 & 30 & $120($ total $2 \mathrm{~h})$ & $2 / 10$ & 80 & \\
\hline
\end{tabular}

*DHR: Drug hypersensitivity reactions

Table 3: Rapid desensitization by modified dose/the estimation optimal under-threshold dose (80 mg isoniazid) every 30 min until the usual daily dose (400 $\mathrm{mg}$ isoniazid) was reached

\begin{tabular}{llllll}
\hline Step & Time (min) & Cumulative time (min) & Drug concentration & Dose (mg) & 80 \\
\hline 1 & 0 & 0 & $2 / 10$ & 80 & 80 \\
2 & 30 & 30 & $2 / 10$ & 80 & 160 \\
3 & 30 & 60 & $2 / 10$ & 240 & 30 \\
4 & 30 & 90 & $2 / 10$ & 80 & 400 \\
5 & 30 & $120($ total 2 h) & $2 / 10$ & 80 & \\
\hline
\end{tabular}

Finally, the treatment for Case-1: Isoniazid was $80 \mathrm{mg}$ orally, every $30 \mathrm{~min}$, until the usual daily dose (400 $\mathrm{mg}$ isoniazid) was reached (Table 3), simultaneously with other regimen of ATD. The suggestion to the patient was should be carefully and highly awareness to DHR.

\section{Case - 2}

A 31-year-old female patient came to Wangaya Hospital due to her experienced urticaria, pruritus $60 \mathrm{~min}$ after taking ATD (450 mg rifampicin, $1000 \mathrm{mg}$ pyrazinamide, $750 \mathrm{mg}$ ethambutol, $400 \mathrm{mg}$ isoniazid, and $10 \mathrm{mg}$ pyridoxine) as a single dose for PTB treatment. The patient presented overall a good condition with hemodynamic was stable. During the anamnesis, she had a history of drug allergy to penicillin. Based on the clinical manifestation, the patient was diagnosed as a mild hypersensitivity reaction related to ATD (Table 4).

The treatment for the patient was the immediate discontinuing of the ATD and giving orally $4 \mathrm{mg}$ methylprednisolone twice daily and $10 \mathrm{mg}$ loratadine once daily for 3 days treatment.

To confirm the offending drugs of DHR by performing DPT at hospital. DPT for each component of ATD (isoniazid, ethambutol, pyrazinamide and rifampicin) were performed to determine the offending drug and the threshold dose. DPT was performed after clinically stable (no signs and symptoms of DHR). After 5 days clinically stable (wash period), the patient returned to hospital for DPT of ATD. The patient signed an informed consent form and admitted for 1 day care for DPT. There was no DHR related to isoniazid, pyrazinamide, and rifampicin during performing the DPT. There was DHR related to ethambutol (Table 5).

DHR occurred at the step 3 of DPT, cumulative time $60 \mathrm{~min}$, drug concentration 3/10, with the dose $225 \mathrm{mg}$ (threshold dose). DPT result was considered positive because there were some symptoms or signs of an immediate drug reaction as described previously were documented (urticaria and pruritus) at about $30 \mathrm{~min}$ after the last dose was administered. The under-threshold dose of ethambutol based on DPT was one step below the dose on step 3 (225 mg) with drug concentration $3 / 10$. The dose was $150 \mathrm{mg}$ ethambutol. Therefore, rapid desensitization with modified dose or the estimation of safe and optimal under threshold dose performed by giving $150 \mathrm{mg}$ ethambutol each 30 min until the usual daily dose was reached (750 mg ethambutol) (Table 6).

Finally, the recommended therapy for the case-2 was by continuing giving ATD with modified dose of ethambutol (Table 6), simultaneously with other regimens of ATD and some suggestions that the patient should be careful with a highly awareness due to DHR.

\section{DISCUSSION AND THE LITERATURE REVIEW}

DHR has increased dramatically worldwide. DHR is a subgroup of adverse drug reaction that characterized by reproducible symptoms and/or signs initiated by drug at a dose that is normally tolerated $[14,19,20]$. Multidrug antituberculosis regimens are associated with various clinical manifestations such as urticaria, generalized pruritus, maculopapular exanthema, lichenoid eruptions, fixed drug eruption, acute generalized exanthematous pustulosis, Stevens-Johnson syndrome, and toxic epidermal necrolysis [21-23].

The offending drug could be clarified by history taking and the definite diagnosis based on DPT result that should be performed at hospital. DPT is a controlled drug administration to patient with a history of DHR. DPT consists of orally or injectly, increasing doses of the suspected offending drug, once every $30 \mathrm{~min}$ until the usual daily dose is administered or symptoms of DHR occur. DPT is used as "gold standard" to establish the diagnosis of DHR. It may estimate the safe and optimal threshold dose $[15,16]$.

Rapid desensitization is recommended for the treatment of DHR. It is a strategy of cautiously administering a medication to patients who have a low likelihood of being allergic to it. Rapid desensitization is to 
Table 4: Data of the patient (Case 2)

\begin{tabular}{|c|c|c|c|c|c|c|c|}
\hline Case & Sex & Age (years) & ATD regimen & IgE total $(\mu \mathrm{g} / \mathrm{L})$ & Onset of reaction & Clinical manifestation & Diagnosis \\
\hline 2 & Female & 31 & $\begin{array}{l}\text { ATD: } \\
450 \mathrm{mg} \text { rifampicin, } \\
1000 \mathrm{mg} \text { pyrazinamide } \\
750 \mathrm{mg} \text { ethambutol, } \\
400 \mathrm{mg} \text { isoniazid, } \\
10 \mathrm{mg} \text { pyridoxine } \\
\text { As a single dose }\end{array}$ & 328 & $60 \mathrm{~min}$ & $\begin{array}{l}\text { Urticaria, pruritus } \\
\text { History; drug allergy (+) } \\
\text { The offending drug was penicillin }\end{array}$ & Mild DHR \\
\hline
\end{tabular}

Table 5: Drug provocation test of $\mathbf{7 5 0}$ mg ethambutol

\begin{tabular}{lllllll}
\hline Step & Time (min) & Cumulative time (min) & Drug concentration & Dose (mg) & Cumulative dose (mg) & DHR \\
\hline 1 & 0 & 0 & $1 / 10$ & 75 & 75 & Mild DHR (+) \\
2 & 30 & 30 & $2 / 10$ & 150 & 225 & \\
$3^{*}$ & 30 & 60 & $3 / 10$ & 225 & 650 & 700 \\
4 & 30 & 90 & $2 / 10$ & 150 & 750 \\
5 & 30 & 120 & $2 / 10$ & 150 & \\
\hline
\end{tabular}

"DHR: Drug hypersensitivity reaction

Table 6: Rapid desensitization by modified dose or the estimation safe and optimal under-threshold dose (150 mg ethambutol) each $30 \mathrm{~min}$, until the usual daily dose (750 $\mathrm{mg}$ ethambutol) was reached

\begin{tabular}{|c|c|c|c|c|c|}
\hline Step & Time (min) & Cumulative time (min) & Drug concentration & Dose (mg) & Cumulative dose (mg) \\
\hline 1 & 0 & 0 & $2 / 10$ & 150 & 150 \\
\hline 2 & 30 & 30 & $2 / 10$ & 150 & 300 \\
\hline 3 & 30 & 60 & $2 / 10$ & 150 & 450 \\
\hline 4 & 30 & 90 & $2 / 10$ & 150 & 600 \\
\hline 5 & 30 & 120 & $2 / 10$ & 150 & 750 \\
\hline
\end{tabular}

reintroduce the drugs cautiously, by giving the drug in stepwise fashion and hence not cause a severe DHR. If the DHR occurs, it is hoped that it is minor and easily treated. Most rapid desensitization approach may be carried out in an outpatient setting without intravenous access, but with full preparation to come back to hospital immediately to treat anaphylactic reactions. The initial dose is mostly about $1 / 100$ of the usual dose or as small as possible but reliable (our starting dose is $1 / 10$ of the usual dose). Doses are usually administered at $30 \mathrm{~min}$ intervals until the usual daily dose is administered or symptoms of a drug reaction occur. Before each dose, the patient should be questioned and examined for symptoms and signs of DHR $[13,16,19,24]$.

DPT and the first rapid desensitization should be performed at hospital by physicians who are familiar with the standard operational procedure and with the treatment of anaphylaxis. It could be continued as an outpatient with some suggestions $[13,15,16,19,24]$.

In this case report: Case 1; a 27-year-old male patient, experienced urticaria, generalized pruritus $60 \mathrm{~min}$ after taking the ATD and the patient with stable hemodynamic, he was also with previous of drug allergy but the offending drug was unclear. The definite diagnostic was confirmed by DPT result. The DPT result was concluded that the patient was hypersensitive to isoniazid with the estimation of safe and optimal under-threshold dose $80 \mathrm{mg}$.

Case 2; a 31-year-old female patient, experienced urticaria, pruritus 60 min after taking the ATD and the patient with the stable hemodynamic, she was also with previous history of drug allergy to penicillin. The definite diagnostic was confirmed by DPT result and the offending drug (ATD) was ethambutol. Therefore, clinically case- 2 was confirmed with DHR related to ethambutol with the estimation of safe and optimal under-threshold dose $150 \mathrm{mg}$ ethambutol.

The recommended therapeutic approach for:
Case 1; rapid desensitization as the therapeutic approach by giving $80 \mathrm{mg}$ isoniazid orally every $30 \mathrm{~min}$, until the usual daily dose $(400 \mathrm{mg}$ isoniazid) was reached and simultaneously with $450 \mathrm{mg}$ rifampicin, $1000 \mathrm{mg}$ pyrazinamide, $750 \mathrm{mg}$ ethambutol, and $10 \mathrm{mg}$ pyridoxine as a single dose.

Case 2; rapid desensitization as the therapeutic approach by giving $150 \mathrm{mg}$ ethambutol orally every $30 \mathrm{~min}$, until the usual daily dose (750 mg ethambutol) was reached simultaneously with $450 \mathrm{mg}$ rifampicin, $1000 \mathrm{mg}$ pyrazinamide, $400 \mathrm{mg}$ isoniazid, and $10 \mathrm{mg}$ pyridoxine as a single dose.

The clinicians should be aware of DHR risk during the patient treatment and awareness of the risk groups may reduce the incidence of serious drug-related hypersensitivity reactions. By giving the information to the patient and their family about the DHR risk and coming back to the hospital as soon as possible, when DHR or another adverse effect occurred.

\section{CONCLUSIONS}

The necessity utilization of multidrug regimens has been associated with increased risk of DHR. DHR has various clinical manifestations and it is unpredictable. It should avoid unnecessary drug interruption or suboptimal treatment, in order not to lead a treatment failure or resistance. Diagnosis DHR based on anamnesis (history taking) and to confirm the offending drug, threshold dose by performing DPT. Rapid desensitization is the recommended therapeutic approach.

\section{ACKNOWLEDGMENT}

The author appreciates to all the staffs in Merpati Clinic, Department of Internal Medicine at Wangaya Hospital in Denpasar, Bali, Indonesia, for a good team work, pulmonologist and the staffs at Department of Pulmonology at Wangaya Hospital in Denpasar, Bali, Indonesia. The 
author would also like to thank to the patients and their family, Director Wangaya Hospital for all of the supports.

\section{CONFLICTS OF INTEREST}

The author declared that there are no conflicts of interest related to this study.

\section{AUTHORS' CONTRIBUTIONS}

Ketut Suryana made substantial contributions to conception, acquisition of data, took part in drafting the article or revising it critically for important intellectual content, final approval of the version to be published, and agreed to be accountable for all aspects of the work.

\section{AUTHORS' FUNDING}

The author received no specific funding for this work.

\section{REFERENCES}

1. Fei CM, Zainal H, Ali IA. Evaluation of adverse reactions induced by anti-tuberculosis drugs in hopsital pulau Pinang. Malays J Med Sci 2018;25:103-14.

2. Venkateswarlu K, Tiwari K, Mamatha E, Vivek S, Shravan P. Study of adverse drug reactions in tuberculosis patients. J Pharma Res 2017;6:61-5

3. Honnaddi UC, Honnaddi MU, Tharangini SR, Hossain T, Somani R. Adverse drug reactions to first line anti-tuebrculosis drugs-a pharmacovigilance study. Int J Pharmacol Res 2016;6:51-4.

4. Health Ministry Republic of Indonesia. Current Status of Integrated Community Based TB Service Delivery and the Global Fund Work Plan to Find Missing TB Cases. Indonesia: Indonesia National TB Program, Health Ministry Republic of Indonesia; 2017.

5. Johansson SG, Hourihane JO, Bousquet J, Koomen CB, Dreborg S, Haahtela $\mathrm{T}$, et al. A revised nomenclature for allergy an EAACI position statement from the EAACI nomenclature task force. Allergy 2001;56:813-24.

6. Singh A, Sayedda K, Ahmed QS. Comparison of adverse drug reactions of antitubercular drugs in category 1 tuberculosis patients between daily and intermittent regimen and its impact on outcome. J Res Med Dent Sci 2017;5:6-12.

7. Gulbay BE, Gurkan OU, Yildiz OA, Onen ZP, Erkekol FO, Baccioglu A, et al. Side effects due to primary antituberculosis drugs during the initial phase of therapy in 1149 hospitalized patients for tuberculosis. Respir Med 2006;100:1834-42.

8. Behera C, Krishna K, Singh HR. Antitubercular drug-induced violent suicide of a hospitalized patient. BMJ Case Rep 2014;2014:1-3.

9. Alqahtani JM, Assad AM. Anti-Tuberculous drugs and susceptibility testing methods: Current knowledge and future challenges. J Mycobac Dis 2014;4:1-6.

10. Aberer W, Bircher A, Romano A, Blanca M, Campi P, Frenandez, et al. Drug provocation testing in the diagnosis of drug hypersensitivity reactions: General considerations. Allergy 2003;58:854-63.

11. Bianchi PG, Aun MV, Galvao VR, Castells M. Rapid desensitization in immediate hypersensitivity reaction to drugs. Curr Treat Options Allergy 2015;2:268-85.

12. Vaghela JH, Nimbark V, Barvaliya M, Mehta H, Chavada B. Antituberculosis drug-induced fixed druh eruption: A case report. Drug Saf Case Rep 2018;5:23

13. Gholami K, Kamali E, Hajiabdolbaghi M, Shalviri G. Evaluation of anti-tuberculosis induced adverse reactions in hospitalized patients. Pharm Pract 2006;4:134-8.

14. Messaad D, Sahla H, Benahmed S, Godard P, Bousquet J, Demoly P. Drug provocation tests in patients with a history suggesting an immediate drug hypersensitivity reaction. Ann Intern Med 2004;140:1001-6.

15. Limsuwan T, Castells MC. Outcomes and safety of rapid desensitization for chemotherapy hypersensitivity. Expert Opin Drug Saf 2010;9:39-53.

16. Castelss M. Rapid desensitization for hypersensitivity reactions to medications. Immunol Allergy Clin N Am 2009;29:585-606.

17. Macy E, Romano A, Khan D. Practical Management of antibiotic hypersensitivity in 2017. J Allergy Clin Immunol Pract 2017;5:577-86.

18. Chiriac AM, Demoly P. Drug provocation tests: Up-date and novel approaches. Allergy Asthma Clin Immunol 2013;9:12

19. Solensky R. Desensitization with antibiotics. In: Pichler WJ, editor. Drug Hypersensitivity. Basel: Karger; 2007. p. 404-12.

20. Garvey LH, Ebo DG, Kroigaard M, Savic S, Clarke R, Cooke P, et al. The use of drug provocation testing in the investigation of suspected immediate perioperative allergic reactions: Current status. Br J Anaesth 2019;123:e126-34

21. Farazi A, Sofian M, Jabbariasl M, Keshavarz S. Adverse reactions to antituberculosis drugs in Iranian tuberculosis patients. Tuberc Res Treat 2014;2014:1-6.

22. Hu X, Zhang M, Bai H, Wu L, Chen Y, Ding L, et al. Antituberculosis drug-induced adverse events in the liver, kidneys, and blood: Clinical profiles and pharmacogenetic predictors. Clin Pharmacol Ther 2018;104:326-34.

23. Amin S, Mishra V, Desai M, Solanki R. Pattern of adverse drug reactions and its potential impact on drug resistant tuberculosis patients at a tertiary care teaching hospital in Western India. Clin J Pharmacol Pharmacother 2018;1:15-20.

24. Cernadas JR, Brockow K, Romano A, Aberer W, Torres MJ, Bircher A, et al. General considerations on rapid desensitization for drug hypersensitivity-a consensus statement. Allergy 2010;65:1357-66. 